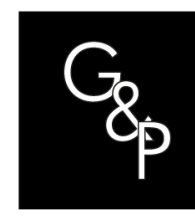

\title{
Interfaces and changes in the institutionalization process of special coffee in Brazil
}

\section{Interfaces e mudanças no processo de institucionalização do café especial no Brasil}

\author{
Josué Pires de Carvalho', Jorge Luis Sanchez Arevalo² (D), João Luiz Passador ${ }^{1}$ \\ ${ }^{1}$ Universidade de São Paulo - USP, Programa de Pós-graduação em Administração de Organizações, Ribeirão \\ Preto, SP, Brasil. E-mail: josue.carvalho@ifb.edu.br; jlpassador@usp.br \\ ${ }^{2}$ Universidade Federal de Mato Grosso do Sul - UFMS, Grupo de Estudos sobre Comércio Internacional, \\ Desenvolvimento e Finanças, Campo Grande, MS, Brasil. E-mail: jsarevalo@hotmail.com
}

How to cite: Carvalho, J. P., Arevalo, J. L. S. \& Passador, J. L. (2020). Interfaces and changes in the institutionalization process of special coffee in Brazil. Gestão \& Produção, 27(2), e4751.

https://doi.org/10.1590/0104-530X4751-20

\begin{abstract}
This study analyzes the importance of the geographical indication (GI) process and other efforts in favor of the institutionalization process of special coffee in Brazil. The study is justified by the fact that Brazil is a world reference in coffee production and in what refers to the special coffee production, the market is promising. The term special coffee has a connotation of a segment type where the quality and experience are privileged, this consumption being differentiated. The Northwest of Minas (MG), Alta Mogiana (SP) and Matas de Minas (MG) regions were chosen for the analysis, which are the most representative in the national scenario. The results show a positive advance in favor of the institutionalization process, in which the main agents involved play an important role, namely, the government, entrepreneurs and producers.
\end{abstract}

Keywords: Special coffee; Geographical indication; Organizational field.

Resumo: Este estudo analisa a importância do processo de indicação geográfica (IG) e demais esforços em prol do processo de institucionalização do café especial no Brasil. O estudo se justifica pelo fato de o Brasil ser referência mundial na produção de café, e no que se refere a produção de café especial o mercado é promissor. O termo café especial tem como conotação um tipo de segmento onde se privilegia a qualidade e experiência, sendo esse consumo diferenciado. As regiões Noroeste de Minas (MG), Alta Mogiana (SP) e Matas de Minas (MG) foram escolhidas para a análise, as quais são as mais representativas no cenário nacional. Os resultados evidenciam um avanço positivo em favor do processo da institucionalização, na qual os principais agentes envolvidos cumprem um papel importante, quais são, o governo, empresários e produtores.

Palavras-chave: Café especial; Indicação geográfica; Campo organizacional.

Received Apr. 1, 2018 - Accepted July 12, 2018

Financial support: None. 


\section{Introduction}

\subsection{Importance}

Coffee is one of the most traded tropical agricultural products in the world. Until 2014 the Brazilian coffee production represented $32 \%$ of the world production (FAO, 2018). For its part, consumption in the world has increased by $1.3 \%$ per year since 1980 (ICO, 2018). In Brazil coffee is cultivated in several states, the most representative being the state of Minas Gerais and São Paulo. Being, the state of Minas Gerais is the area for this study.

On the theoretical side, this research lands on the organizational studies field, focusing on the institutional theory's contributions. By linking the challenges, advancement possibilities and eventual impasse in the relationship between the State and private agents in the search to guarantee and promote adequate arrangements for socioeconomic development and the productive continuity. In relation to the study on screen, highlight those focused on the value aggregation in Brazilian coffee production with impact not only for the agribusiness itself, but also for the medium and small family-based producers.

The research sought to understand how organizations inserted into "regions" focused on special coffees' production are influenced by institutional actors, especially in the process of acquiring a $\mathrm{Gl}$, and how this context affects the process of institutionalization of special coffee in Brazil, considering to this effect all the actors involved.

At this point highlighting that acquiring a GI suffers institutional influence not only on the tendency to increasingly expand its membership by the productive sector, but also by the fact that the adoption of Gls would imply commitment to new rules, routines, ways of doing and acting that could even contradict previous practices. The entrepreneur aspect undertaken by the government through public institutions, whether it being the state government, SEBRAE or others, play an important role in such a way that the coercive aspect of the State is seen.

Considering the presented context, the following guiding question arises: How do institutional aspects influence and are mobilized in the acquisition of a GI in the context of an organizational field?

To this end, from the theoretical approach of organizational institutionalism, more closely as their notions of isomorphism and institutional field to highlight the role of the state and other actors in the process. In general, the objective of the study is to understand how the adoption of Gls and other efforts, influence, whether positively or negatively, the special coffee process of institutionalization in Brazil. Promoting in this context the State coercive role (the obligation to comply with laws and rules) and its entrepreneurial action in the interaction with the other actors.

\subsection{Rationale}

The present study is justified by the necessary and enriching differentiation of the approaches aimed at the analysis and understanding of the "Geographical Indications - Gl" phenomenon various dimensions and specificities, especially in the coffee production with added value and socioeconomic impact. 
Studies on the sector were done by areas or related topics, addressing mainly issues related to efficiency and economic viability, productive arrangements, premium price paid to the producer, transaction costs, and grain export. In this study, the importance of the added value of the grain, defined in this case as special coffee, is implied in the importance of the GI acquisition in the coffee regions.

It is noteworthy that the production of gourmet coffee associated with the acquisition of Gls was little studied from the perspective of organizational institutionalism, which further reinforces the importance of the research. Moreover, considering the field formation and institutional factors that affect the same, it seems to constitute a relevant research opportunity, which can contribute to the knowledge framework that has been generated around the topic.

In addition, it is observed that previous studies tend to focus in isolated cases, usually focused on a specific production region in Brazil. On the contrary, in this study it was intended to develop a multi-case approach to include several coffee regions.

It is expected, with this approach, to contribute with the enlightenment on the adoption of instruments that can add to the institutional strengthening and socio-economic maintenance of the producers' activities and others involved in the differentiated coffee production chain. As well as extending the scope of institutional theory, empirically broadening and testing its applicability to the Gls acquisition by coffee producing regions in Brazil.

\section{Theoretical framework}

\subsection{The organizational field}

The organizational field is characterized as the conjunction of the component organizations of an institutional segment, comprising clients, suppliers, competitors and regulatory bodies, which influenced by them, are directly or indirectly impacted (DiMaggio, 1991).

In this sense, external agents to an organization or a group of them can even interfere in its behavior and structure, through norms and even the transmission of values. This process becomes more evident as the field reaches its institutionalization phase, in which case the presence of interorganizational bonds and shared values is accentuated (Yorozu, 2017; Simão et al., 2017).

The notion of organizational field linked to organizational legitimacy, is of fundamental importance in the institutional sedimentation process (Cruz-Suárez et al., 2014). In addition, it seeks to add a symbolic dimension in the analysis of the exchange with the environment relation, which organizations promote in their quest for survival (Hollway et al., 2017; Duarte \& Tavares, 2012).

It is understood that, initially the organizations are in isolation, and that given the specialization and perception of belonging to a field, they tend to share values. This process tends to strengthen the field institutionalization. Evidently, organizations begin to recognize the mutual and gradual importance of the proximity. Consequently, the evolution of the relations becomes accentuated, and the points of contact tend to converge, strengthening the sharing of values (see Figure 1).

In addition, organizations become more similar (isomorphic) to each other from the implication of "powerful forces" acting in a structured field. This observed process may be more relevant when it comes to the same activity sector and composed of different 
organizations. It is emphasized that this process tends to impact structures, work practices, organizational behavior, goals and strategies which promotes the "isomorphism" condition.

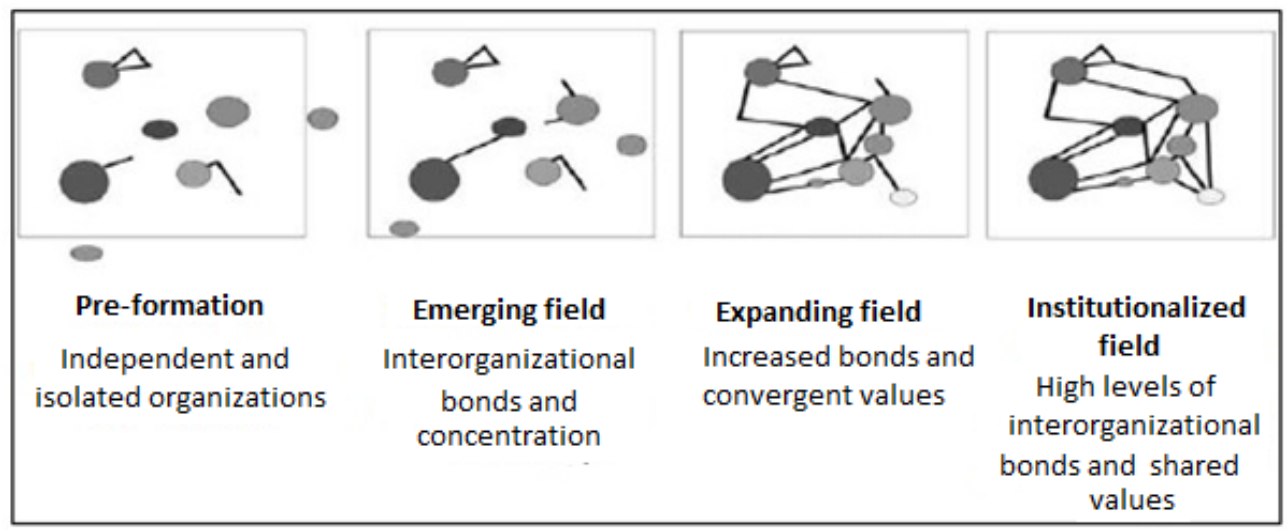

Figure 1. Formation stages of an organizational field . Source: Elaborated from Gonzalez \& Martins (2017), and Gomes \& Vieira (2009).

\subsection{Isomorphism types}

\subsubsection{Coercive isomorphism}

It is the result of political influences and the legitimacy question. The organizations may suffer expressly coercive pressure or even in the persuasion form, invitation to joint participation, manifested formally or informally arising from dominant organizations that holds some kind of demanding resource or by socially determined expectations.

Teo et al. (2003), when studying the adoption of new technologies, pointed to evidence that would reinforce the perception that, through domination, resource-holding organizations (corporate headquarters and regulators) may exert coercion in exchange relationships. The authors emphasize that customers and suppliers can exert influence for the use of a certain technology on a company when it is dependent on the first in resources. Thus, the maintenance of trade relations of mutual benefit, would then be a form of coercive pressure.

On the other hand, to link the issue with the participation of governments more closely, the state, along with the other agents, tends to coerce a number of organizations through the implementation of public policies, highlighting its role in the isomorphic changes (Machado da Silva \& Fonseca, 2010).

For example, researches highlight the importance of the governmental hierarchy and its organs as a source of influence on organizations, considering the adoption of information technologies, through political manipulation and budgetary resources (Rodriguez et al., 2007). Moreover, the legitimacy of standards regarding the practices, can also result from the development of public policies (Cruz-Suárez et al., 2014; Diniz et al., 2009), something determinant in the special coffee context, which is the question of study. 


\subsubsection{Normative Isomorphism}

The source of normative isomorphic change comes mainly from the professionalization and recognition of its importance. These points act as a collective force of a profession/occupation members that defines the conditions and methods of their own work (Doluwarawaththa Gamage \& Gooneratne, 2017). These influences are determinant in organizations.

Although the practices of a particular profession may be different in one organization, professionals linked to a profession tend to replicate similar behavior even in different companies. This reality can derive and foster the relationship through networks of professionals that constantly update themselves and spread new work forms as they are composing their staff.

In this sense, considering the similarity in the managers' case in different organizations in relation to their networks of work/relationships and formal education, the response to problematic situations tends to be similar, given the sharing of practices. In this sense, organizations would act isomorphically in function of problems that have not yet allowed their own coping solutions (Prado-Roman et al., 2018; Hüther \& Krücken, 2016).

\subsubsection{Mimetic isomorphism}

In this type of isomorphism, the pressures come from the positive perception that organizations have of others. Thus, in order to consider them to be more successful or legitimate, organizations perceive the need to insert itself in the context, that is, to model after other organizations. In the view of DiMaggio (1991) DiMaggio \& Powell (2005) there are situations of an organization being taken as a model, that in reality do not result from the desire for the organization's position, but of the effort displayed, aiming at strengthening the organization in the inserted segment.

In this same context, companies use recurring imitation to produce new products, to elaborate processes and methods, to outline ways of organizing and exploiting new markets (Yorozu, 2017). At this point, the cultural-cognitive pillar associated with the mutation of the isomorphic mimetic is highlighted, where the activities of institutions are taken culturally and adhered to in the organizations' dynamics (Rupidara \& Darby, 2017). Hence the emphasis attributed to symbols and meaning, as individuals do not absorb the external reality as given ontologically; but taking into account a socially shared structure of meanings.

Linking this part of the theory with the proposed study, it is integrative and systemic character, by considering it to be a potentiating prospect of elucidation of stakeholders. In view of this, while recognizing the challenges of time, diverse resources demanded and even dangers when relating to the epistemological context, the proposed study seek to understand the institutionalization phenomenon of the special coffee. Undoubtedly, categories such as organizational field, isomorphism, legitimacy and institutional entrepreneur, are simultaneously determinant concepts.

\subsection{Formalization of research focus}

Considering that an organizational field advances in its stages of institutionalization concomitant to the increase of the interactions and diffusion of shared understandings and beliefs, adopted practices, rationalized myths by the present organizations, in order 
to make them more and more similar (Gamage \& Gooneratne 2017; Tolbert \& Zucker, 1998), we have the following propositions:

- Proposition 1. The adoption of the GI registration for coffees occurs under certain structuring conditions arising from the institutionalization process of the organizational field;

- Proposition 2. Organized entities in the coffee production tend to be forced to adhere to the $\mathrm{GI}$ registry by government agencies and organizations that have resources and power, due to coercive pressures. It is considered that the coercive pressures can come from dominant organizations, possessing resources and power present in the organizational field;

- Proposition 2A. Interest in GI registration by the State and other resource-earning organizations tends to exert coercive pressures for their use in dependent coffee organizations;

- Proposition 3. Coffee producers' associations that seek premium prices tend to seek GI registration in accordance with professional and governmental organizations, due to the occurrence of normative isomorphism;

- Proposition 4. Coffee grower organizations tend to seek legitimacy by registering a $\mathrm{Gl}$ as they identify an $\mathrm{GI}$ holding organization as a successful model in a field. Thus, use of GI by prominent organizations in the field can exert pressure of the mimetic type on the other entities;

- Proposition 5. In addition to coercive pressures, the State, through its agents and agencies, engages in proactive actions of institutional entrepreneurship through the mobilization of efforts and resources, and through the sensitization discourse to adopt a GI for coffee.

The previous proposition is strengthened by the fact that the institutional entrepreneur (whether individuals or organizations) acts by mobilizing resources and elaborating discourses of persuasion, implying changes in institutions (Rahmah 2017; Rupidara \& Darby, 2017; DiMaggio, 1991).

Importantly, the results using the criterion of "big influence" and "small influence" is based on the relationship observed in the research, being used to such criteria, interviews and texts related to the study.

\section{Methodology}

\subsection{Study context}

The scope of the research covers three coffee regions, namely: (a) the northwestern part of the Minas Gerais state, (b) the Zona da Mata, also in the state of Minas Gerais, and (c) the Alta Mogiana, state of São Paulo. It should be noted that the first two producing regions have $\mathrm{Gl}$ of coffee produced by them; while the last region mentioned above is in the process of achieving geographical certification.

The choice of the above-mentioned coffee regions was due to convenience criteria, that is, to select the most profitable research locus; and whose actors made themselves available to collaborate with the data provision necessary for the reflections that were and are understood in the research scope. Nevertheless, it should be pointed out that the expedient of choosing certified coffee regions, and a single region that does not yet 
have a geographical indication, is justified by the need to have elements to compare the evident institutionalities in each of the analytical loci which covers the research.

It is important to reiterate that the coffee regions contemplated in this study are among the main poles of production of special coffees in Brazil. Thus, it is very important to undertake efforts which have the purpose to shed light to the dynamics and characteristics of these regions. Consequently, it is important to regard important elements so that the planning can be more efficient, and in turn, imply the promotion of coffee production in emerging localities, such as the states of Rondônia and Bahia, for example.

Data utilized in this study are from the following sources: (a) participant observation and systematic with leading players who are based in the special coffee producing regions; (b) documents provided by the investigated players (such as documents, minutes of meetings, statutes, photographic records, folders and the likes); (c) exploratory and in-depth interviews with players, which guided the institutions definition in the coffee regions investigated in this paper.

As an instrument for directing the in-depth interviews, a protocol with guiding questions was used to understand how institutional factors influence the adoption of geographical indication (Blakeney et al., 2013) in the context of the organizational field under analysis, in each one of the coffees producing regions considered in this research.

As a subterfuge for a greater and better approximation in relation to the subject investigated, exploratory interviews were conducted with privileged informants from the producing regions investigated. The interviews were not recorded and served to check previous information, contributing to the refinement of the protocol with guiding questions effectively engaged in data collection.

Agents interviewed effectively in this step were as follows: two pioneers of the third wave coffee branch in Brazil; two researchers who participate in projects focused on the coffee area, financed by Funcafé; a pioneer in the segment, certifier of SCAE in Brazil, producer, Q-Grader and owner of Cafeteria; a producer and owner of an accredited warehouse, with a pioneer family in the production of coffee in the Minas Gerais cerrado region.

Part of the interviewees in the preliminary and exploratory stage of the research composed, in a second moment, the set of agents that were effectively interviewed with greater rigor and detail richness. Thus, interviews of this last group of agents were recorded for subsequent transcription, and to use in the research results. The agents investigated (see Table 1) in the stage of effective data collection for the survey were the following (interview script, see Appendix A):

Table 1. Interviewed agents who participated in the survey.

\begin{tabular}{lcc}
\multicolumn{1}{c}{ INTERVIEWED AGENT } & LOCATION & DURATION \\
\hline $\begin{array}{l}\text { 1. National reference in the field } \\
\text { of special coffee, Q-grid, owner } \\
\text { of third wave cafeteria, producer } \\
\text { of the cerrado }\end{array}$ & Belo Horizonte-MG & 39 minutes, 02 seconds. \\
\hline $\begin{array}{l}\text { 2. Cerrado Mineiro IG's } \\
\text { consultant }\end{array}$ & Patrocínio-MG & 37 minutes, 45 seconds. \\
\hline $\begin{array}{l}\text { 3. Producer and vice-president } \\
\text { "AMSC" }\end{array}$ & Alta Mogiana Region & 41 minutes, 12 seconds. \\
\hline
\end{tabular}


Table 1. Continued...

\begin{tabular}{|c|c|c|}
\hline INTERVIEWED AGENT & LOCATION & DURATION \\
\hline $\begin{array}{l}\text { 4. Owner and Barista of third } \\
\text { wave coffee shops, buyer of IG } \\
\text { Alta Mogiana and Cerrado } \\
\text { Mineiro coffees. }\end{array}$ & Ribeirão Preto-SP & $\begin{array}{c}1 \text { hour, } 56 \text { minutes, } \\
23 \text { seconds. }\end{array}$ \\
\hline 5. Expocaccer Representative & Patrocínio-MG & 18 minutes, 26 seconds. \\
\hline $\begin{array}{l}\text { 6. SEBRAE "Matas de Minas'" } \\
\text { representative }\end{array}$ & Patrocínio-MG & $\begin{array}{l}1 \text { hour, } 3 \text { minutes, } \\
16 \text { seconds. }\end{array}$ \\
\hline $\begin{array}{l}\text { 7. Publisher of the "Espresso" } \\
\text { magazine }\end{array}$ & $\begin{array}{l}\text { Belo Horizonte-MG, } \\
\text { International coffee } \\
\text { week. }\end{array}$ & 41 minutes, 03 seconds \\
\hline $\begin{array}{l}\text { 8. Representative of the region } \\
\text { "Alta Mogiana" }\end{array}$ & $\begin{array}{l}\text { Belo Horizonte-MG, } \\
\text { International coffee } \\
\text { week. }\end{array}$ & 27 minutes, 54 seconds. \\
\hline $\begin{array}{l}\text { 9. Owner of accredited } \\
\text { warehouse and producer in } \\
\text { Minas Gerais' cerrado region }\end{array}$ & Patrocínio - MG & 24 minutes, 08 seconds \\
\hline $\begin{array}{l}\text { 10. Producer, consultant Illy and } \\
\text { member of the Matas de Minas' } \\
\text { Council }\end{array}$ & Belo Horizonte & 60 minutes, 01 second \\
\hline $\begin{array}{l}\text { 11. Producer and award winner } \\
\text { in the Minas Gerais' cerrado } \\
\text { region }\end{array}$ & Serra do Salitre - MG & $\begin{array}{c}1 \text { hour, } 28 \text { minutes, } \\
03 \text { seconds }\end{array}$ \\
\hline
\end{tabular}

Source: o autor (2018).

As can be seen in the above table, there were 11 in-depth interviews in the period of 2016 to 2017, which were later submitted to content analysis techniques - as it will be clarified soon, still in this chapter. The ordering of the interviews, for their better analysis and comprehension were performed using the qualitative program Nvivo 12 Pro.

It should be noted that in the period of 2014 to 2017 the study's authors participated in various events and courses related to the sector. Thus, third-wave coffee shops and production properties were visited in the cities of São Paulo-SP, Brasília, Ribeirão Preto-SP, Curitiba-PR and Belo Horizonte-MG, in which it was possible to trace the image of the sector, which was further strengthened through the above-mentioned interviews.

In addition, researchers had the possibility to accompany on-site, in the years 2014 , 2015 and 2016, the International Coffee Week, in which there were major "players" in the coffee industry in Brazil (including the branch of special coffee), with the city of Belo Horizonte/MG as its venue.

The agents chosen for the interview met the convenience criterion, that is, the "players" who, in addition to offering fundamental information to lighten the research problem, volunteered to participate in the research. It is worth considering, as it is appropriate, that agents were duly informed of the strictly academic and scientific character of the research, and they were guaranteed confidentiality in the treatment and analysis of information provided to researcher. 


\section{Results}

\subsection{Background and organizational field formation}

The special coffee segment in Brazil dates back at the beginning of the "special coffee" award promoted by Ernesto Illy in 1992, this being the impulse that initiated the culture of coffee valorization, not only as a grain export, but also inducing the best practices and higher quality. From that time until then, the coffee quality practice competition was disseminated and multiplied throughout the producing regions. Thus, Ernesto Illy can be considered as an actor who contributes in a committed way to the beginning and implementation of institutional changes of the Brazilian coffee market (Battilana et al., 2009).

Also, in this context, and specifically, the importance of the Illy prize initiative is mentioned in interviews with producers and consultants. One of the respondents marks the beginning of that competition in the mining cerrado region:

\footnotetext{
... The Cerrado Mineiro began in 1994 with the Cerrado Coffee brand, when they realized that they needed to promote the Cerrado internationally. And when they started going to the fairs, during this time Cerrado Mineiro had won 2 or 3 Illy contests, until then few people knew the cerrado, because it was a new region, 45 years or so of production, but they already had the response, they went to the international coffee fairs and they were heard "we are from the Cerrado de Minas, we were Illy champions", Illy is an international brand that has respect, so people started to turn their eyes to the cerrado and in this they began to realize that the cerrado had a very important characteristic that was to guarantee the volume supply with high quality [...] (agent interviewed 3).
}

By the same time came, as well as the Illy Prize initiative, the creation of the Brazilian Special Coffee Association - BSCA, from the junction of a group of producers who were already seeking to produce differentiated coffees on their properties. Thus, BSCA sought to promote actions to improve the Brazilian coffee quality and disseminates them abroad. Parallel to this movement emerged the so-called "third coffee wave" that would later requalify production and consumption definitively around the world.

Other relevant actors to the field formation were present at the time, yet still acted very much geared for coffee commodity. At the time there were only a few quality-oriented producers, some cooperatives were forming, big buyers like Illy, ABIC, Embrapa the MAPA the FUNCAFÉ in its first phase and governments acting without focus on product differentiation and in isolation.

Figure 2 looked to clarify the beginning of the process itself, the institutionalization of the field. Thus, in 1992, emerges in the field the embryo from what it would become the first GI of coffee in Brazil, it is CACCER. On the other hand, SEBRAE already dismembered from the federal government starts taking the first steps to support small enterprises and cooperatives began to expand by producing regions, an early organization of movement and assemblage of producers so far still very isolated.

It is in this case, the first movements of recognition and mutual interaction between the actors. Based on this interaction and recognition, Figure 2 attempted to interlink the first actors related to the coffee segment, in turn, of greater and lesser influence in relation to the strengthening of the sector, as well as its impact as a main or secondary 
actor, so far. It is noteworthy during this period that the presence of BSCA gained prominence through its own founding members to begin the process of field influence.

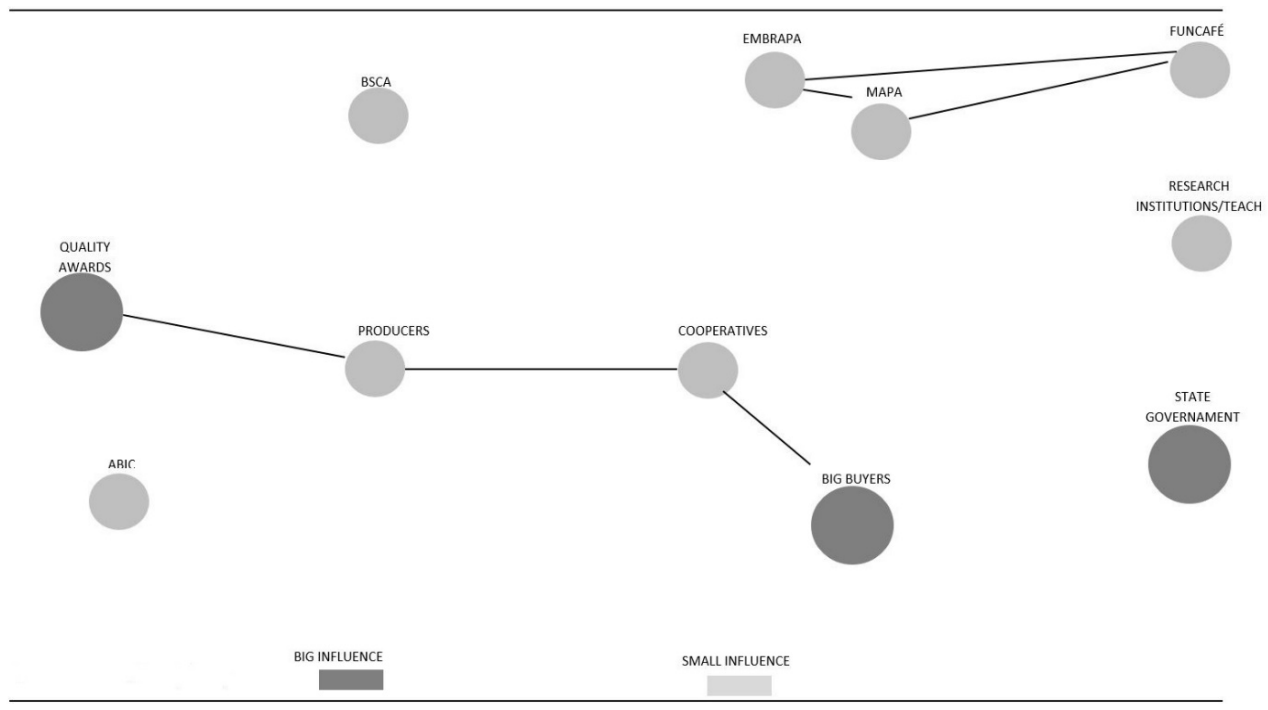

Figure 2. Organizational field of Special Coffee in Brazil (1991-1992), pre-formation fase. Source: the author (2018).

As a consequence, the wave of special coffees reached entities linked to the government (government departments, INPI, MAPA, development agencies, universities, sectoral funds, sector's representative councils) and started to awaken a kind of awareness focused on the opportunity to add value. Such is the case of SEBRAE in different states - Minas Gerais, São Paulo, Paraná - and several producing and selling companies. The promotive action of these institutions would be directly impacting the culture development of special coffee production in Brazil.

Later, from 2003 onwards, a new paradigm begins to be seen in the sector. The first coffee shops of the third wave appear in the city of São Paulo. Coffee shops and pioneering roasters that would become references in Brazil, such as II Café, Baristas Academy, Suplicy Cafés Especiais. Also, the figure of the professional barista appears with more prominence. This professional has since become a key player in the field and with his rise came the political representation and interests constituted within the sector. On the face of it, a new organizational structure and more robust began to be outlined.

Similarly, in 2005 was created the Brazilian Association of Coffee and Baristas. This emerging structure reflected the beginning of a certain niche demand for special coffees within Brazil, something that is more present in part, in the United States and Europe. In that same year, the other element of rupture for the field was the granting of registration of the IP of the Cerrado Mineiro, which was already articulated in the middle as an emerging force.

Likewise, the teaching and research institutions had started their projects and research focused specifically on the coffee quality. In these years, the increase of bonds and approach between actors was more visible and more clearly trimed and in the sense of belonging and identity, as subgroups in the field, mainly (see Figure 3).

The following year, the segment gained prominence with the entry of Expresso Magazine in 2006, this one began to play an important role in this process, being that 
at the time the sector still lacked means of written diffusion. In fact, people used to talk about quality coffee, and there was little understanding of this kind of coffee and where to find it. Thus, at the time two major buyers entered the Brazilian market, Starbucks and Nespresso, each of them with their peculiarity. Highlighting thus the importance of the international investment and its impact on the internal market.

Synthesizing Figure 3, as professional associations, Gls, models of coffee shops and small roasters emerged, rationalizing myths, assimilated discourses, standardized practices, and so many other elements of institutionalization began to exercise mimetic isomorphic prayers in models and practices. Also, coercive in the sense that organizations presenting themselves as leaders ended up disseminating practices such as the quality awards. In addition, normative pressures by means of normative standardization of procedures for certification of baristas, roasters masters, coffee tasters among other professional groups of the sector.

From 2010 to 2016, the organizational field, upon seeing, already presents sufficient elements for its characterization as an institutionalized field. There is a significant expansion of coffee shops and third wave for large and medium cities of the country. Strong expansion of coffee quality contests, special highlight for the Cup of Excellence editions promoted by BSCA in partnership with the Alliance for Coffee Excellence.

Also, there is an increase in consumers' interest in special coffees, as well as courses and training on the beverage. Hence, in the organizational field, producers are observed to be stronger or more influential individually, and through organizational arrangements of representation. Consequently, there is a greater knowledge of the producers, knowing how to sell their product better and with more expertise in the segment.

Regarding teaching and research institutions, UFLA has become one of the exponents of the strengthening and institutional support to the special coffee field. This institution has started its research and extension projects for more than six decades, and currently has more than 100 researchers working in the Research Coffee Consortium in 47 specific projects.

In 2008, the National Institute of Coffee Science and Technology - INCT Café, created by $\mathrm{CNPq}$ and headquartered at UFLA, was created in 2008 as part of the university's initiatives and partnerships aimed at strengthening the research and propagation of knowledge in coffee. Like other INCT's in other areas, the objective of the partnership, was the integration of the main research bodies facing the coffee business to produce innovation, application troubleshooting and industry improvement from the involvement of highly qualified researchers.

The last important initiative of UFLA was the installation in its premises in June 2016 of the InovaCafé Agency, under the coordination of the Embrapa Café. It is a physical space equipped with infrastructure to support and integrate its internal organs for research in coffee and bring the other universities, government and the productive sector closer together. 


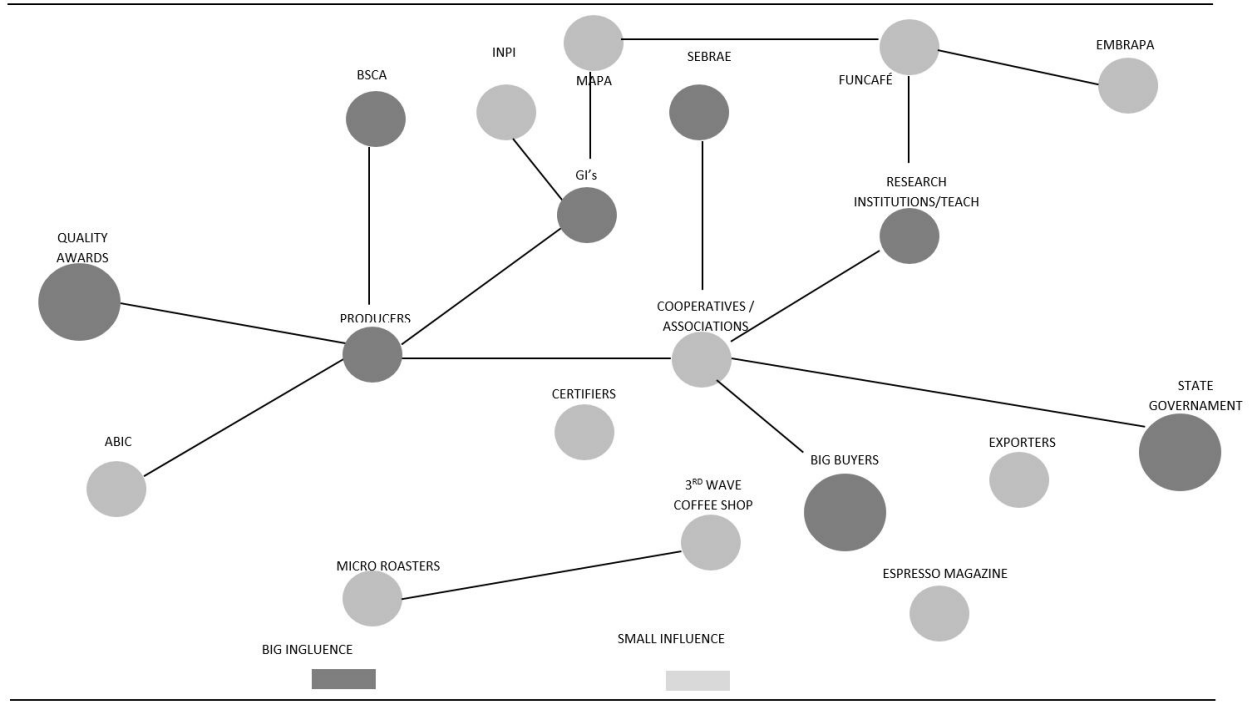

Figure 3. Organizational field of Special Coffee in Brazil (1991- 2009). Source: the author (2018).

In this way, InovaCafé emerges to host and optimize important projects such as the INCT Café itself, as well as the Technological Center for Online Marketing of Coffee and e-Café Brazil, the Market Intelligence Center - CIM, the Training Center in Markets, the Coffee Information and Development Bureau and the Center for Teaching, Research and Extension of Agribusiness Coffee - Cepecafé. All these initiatives have a direct or indirect impact on productivity, quality and knowledge of coffee production in Brazil. The funders and institutional supporters of the agency are the Founder of Resources and Projects - FINEP, UFLA and the Foundation for the Support of Research in Minas Gerais - FAPEMIG.

Other important institutions are the Federal University of Viçosa - UFV, the Agronomic Institute of Campinas - IAC, the Agronomic Institute of Paraná - IAPAR, the Capixaba Institute for Research, Technical Assistance and Rural Extension INCAPER, Bahia Agricultural Development Company - EBDA, Empresa of Agricultural Research of the State of Rio de Janeiro - PESAGRO, and in partnership with UFLA, Embrapa and MAPA form the "coffee research consortium", whose mission is to promote the conjunction of human, physical and financial resources within the scope of research and coffee development.

Specifically in the "coffee research consortium", the state governments, especially the Government of Minas Gerais play an important role, in relation to the Governments of São Paulo and Paraná, as promoters of the product and investors (credit institutions aiming at support for coffee cultivation). Like so, given the greater influence of these actors, the strengthening of Gls is a consequence. Thus, the creation of value in the product is observed, the same that fulfills the role of serving/promoting the opportunity for producers to offer their products in the market.

Synthesizing Figure 4 shows the links of big and small influence of the organizations. In fact, the more producers, cooperatives, associations and roasters interact to promote special coffee in Brazil, the greater the degree of isomorphism in the field as a whole. Moreover, the greater the degree of inter-relation of an agent compared to other, more influential becomes the organizational field. Also, the crucial role of the government stands out at this point. The greater the degree of influence of 
the entities linked to the government, the greater the amount of isomorphic changes, mainly mimetic.

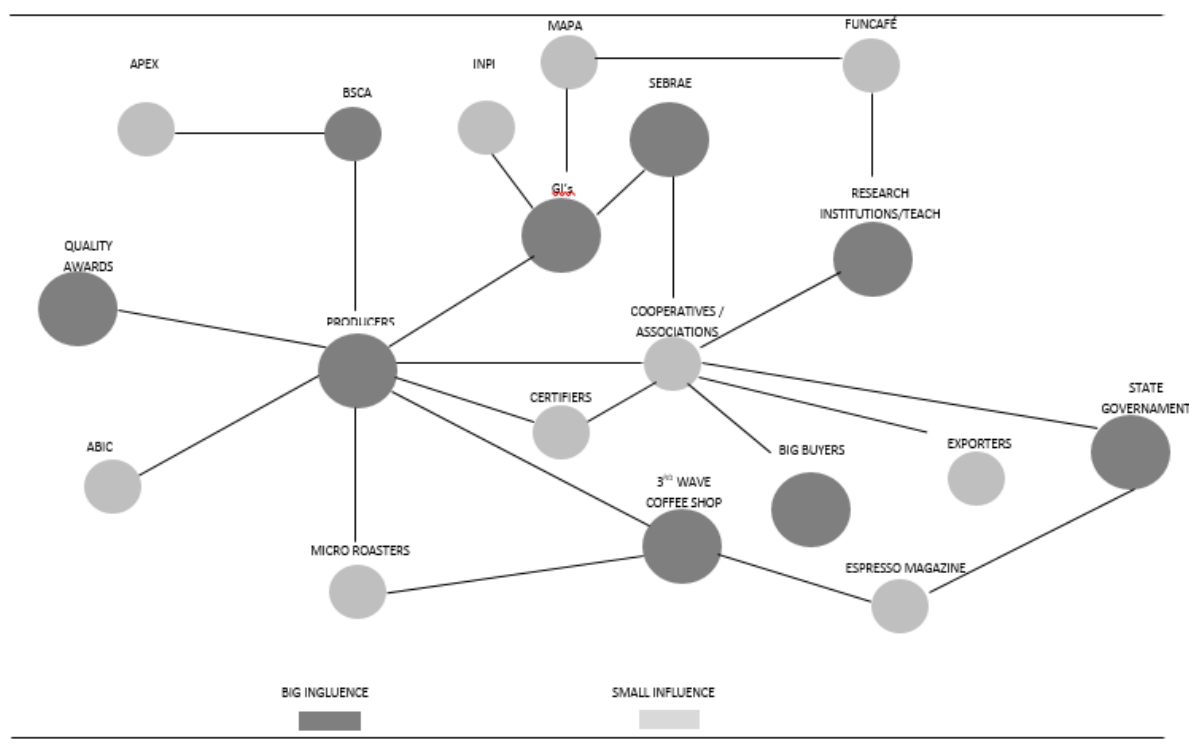

Figure 4. Organizational field of Special Coffee in Brazil (1991- 2017). Source: The authors (2018).

\section{Conclusions}

From the study and in the light of the objectives proposed, it can be concluded that the current stage of special coffee field in Brazil highlights institutionalization and sedimentation elements. The relationships of greater and lesser intensity - shown in the figures by circles - were determined in function of the process evolution of the field formation, as well as of the importance of each institution as agent of the field itself. In order to stablish such a relationship, it is based on the interviewees information, as well as, access to documents provided by them.

The Gls studied had their birth and survival conditions favored by the institutional structure emerged in the field. Also, the acquisition of a $\mathrm{Gl}$ and mainly its maintenance over time tends to depend on a certain structural conjunction that expresses several elements and values necessarily shared among those involved. Obviously, the acquisition of a $\mathrm{Gl}$ corroborates the success and organizational strengthening. This context refers to the discussion that involves propositions 1 and 2 whenever both the normative and coercive pressures are passed on to the coffee organizations that denote interest in the $\mathrm{GI}$ record.

There is a strong occurrence of coercive, mimetic and normative isomorphic pressures in the field which helps to validate proposition 5 . Specifically, when talking about International Coffee Week, it harmonizes with the context of normative isomorphism, specifically, it is verified through this initiation the establishment of conditions, methods and practices relevant to the sector. This context reflects the discussion involving propositions 3 and 4 , where coffee producers' organizations tend to seek legitimacy, considering that the measure that identifies an organization that owns $\mathrm{Gl}$ is seen as a successful model in the field. 
In addition, entrepreneurial actions by the State, especially in the Minas Gerais government structure, are present in the countryside, yet another actor such as SEBRAE seems to exercise institutional entrepreneurship with the stronger producers and other actors of the Brazilian economy with less intensity.

The state coercive force, in the case under discussion, seems to be more related to its relations with entities unrelated to the public sector directly, as is the case of SEBRAE. Also, it was verified that the importance of the Barista, which play an important role, implying the development of techniques that make this product differentiated.

In this way, the entities described as part of the organizational field of coffee engage each other. Thus, intentional action aiming at reaching goals, fit into a dynamic in which the interaction of the entities is strengthened continuously. In short, based on what was described, it is observed that the organizational field has undergone a lot of change, being this positive factor in the sense of observing the actors' commitment.

Finally, the study in question has some limitations, thus providing opportunities for future research. First; there is a limitation of the very nature of qualitative research, in the sense of restrictions on the generalization of results. Second; the quantities of regions considered in the study also relativize the conclusions and assumptions of the study, especially in comparison with the phenomenon in other producing and consuming countries of the special coffee.

\section{References}

Battilana, J., Leca, B., \& Boxenbaum, E. (2009). How actors change institutions: towards a theory of institutional entrepreneurship. The Academy of Management Annals, 3(1), 65107. http://dx.doi.org/10.5465/19416520903053598.

Blakeney, M., Coulet, T., Mengistie, G., \& Mahop, M. T. (2013). Extending the protection of geographical indications: case studies of agricultural products in Africa (pp. 1-372). London: Routledge.

Cruz-Suárez, A., Díez-Martín, F., White-González, A., \& Prado-Román, C. (2014). Analysis of the relationships between organizational legitimacy, its sources and dimensions. Revista Venezolana de Gerencia, 19(65), 9-22.

DiMaggio, P. J. (1991). Constructing an organizational field as a professional project: US art museums, 1920-1940. In W. W. Powell \& P. J. DiMaggio (Eds.), The new institutionalism in organizational analysis (pp. 267-292). Chicago: University of Chihuahua Press.

DiMaggio, P. J., \& Powell, W. W. (2005). A gaiola de ferro revisitada: isomorfismo institucional e racionalidade coletiva nos campos organizacionais. Revista de Administração de Empresas, 45(2), 74-89.

Diniz, E. M. F., Junqueira, A. R. B., \& Prado, O. (2009). Electronic government in Brazil: historical perspective from a structured model of analysis. Journal of Public Administration, 43(1), 23-48.

Doluwarawaththa Gamage, S. D., \& Gooneratne, T. (2017). Management controls in an apparel group: an institutional theory perspective. Journal of Applied Accounting Research, 18(2), 223-241. http://dx.doi.org/10.1108/JAAR-09-2015-0075.

Duarte, D.V ., \& Tavares, B. (2012). Institutionalism and governmental determinations: evidence of isomorphism in technologically based companies. In ENAPG - Meeting of Public Administration and Governance. São Paulo: FGV.

Food and Agriculture Organization of the United Nations - FAO. (2018). Database faostat. Retrieved in 2018, July 2, from http://www.fao.org/faostat/en/\#home 
Gamage, S. D. D., \& Gooneratne, T. (2017). Management controls in an apparel group: an institutional theory perspective. Journal of Applied Accounting Research, 18(2), 1-32.

Gomes, J. P. P., \& Vieira, M. M. F. (2009). The field of electric energy in Brazil from 1880 to 2002. Revista de Administração Pública, 43(2), 295-321. http://dx.doi.org/10.1590/S003476122009000200002.

Gonzalez, R. V. D., \& Martins, M. F. (2017). Knowledge management process: a theoreticalconceptual research. Management \& Production, 24(2), 248-265.

Hollway, J., Lomi, A., Pallotti, F., \& Stadtfeld, C. (2017). Multilevel social spaces: the network dynamics of organizational fields. Network Science, 5(2), 187-212.

Hüther, O., \& Krücken, G. (2016). Nested organizational fields: isomorphism and differentiation among European universities. Research in the Sociology of Organizations, 46, 53-83. http://dx.doi.org/10.1108/S0733-558X20160000046003.

International Coffee Organization - ICO. (2018). Statistics. Retrieved in 2018, July 7, from http://www.ico.org/trade_statistics.asp?section=Statistics

Machado da Silva, C. L., \& Fonseca, V. S. (2010). Organizational competitiveness: an attempt at analytical reconstruction. Journal of Contemporary Management, 14(spe), 33-49.

Prado-Roman, C., Díez-Martín, F., Blanco-González, A., \& Prado-Roman, A. (2018). The origin of the legitimacy of organizations and their determining factors. In C. Berger-Vachon, A. Gil Lafuente, J. Kacprzyk, Y. Kondratenko, J. Merigó \& C. Morabito (Eds.), Complex systems: solutions and challenges in economics, management and engineering. Studies in Systems, Decision and Control (Vol. 125). Cham: Springer. http://dx.doi.org/10.1007/978-3-31969989-9 4.

Rahmah, M. (2017). The protection of agricultural products under geographical indication: an alternative tool for agricultural development in Indonesia. Journal of Intellectual Property Rights, 22(2), 90-103.

Rodriguez, C. L., Diniz, E., \& Ferrer, F. (2007). Government Influence and institutional strategies in the diffusion of innovations in emerging economies. RAE-Journal of Business Administration, 47(1), 10-21.

Rupidara, N. S., \& Darby, R. (2017). Institutional influences on HRM in the Asian business environment: the case of Indonesia. Journal of Asian Business Studies, 11(3), 262-277. http://dx.doi.org/10.1108/JABS-07-2015-0110.

Simão, G. L., Antonialli, L. M., Souza, T. C. C., No., \& Santos, A. C. (2017). Strategic institutional management in dairy cooperatives - a theoretical appointment. Journal of Economics and Rural Sociology, 55(4), 693-710. http://dx.doi.org/10.1590/1234-5678180694790550405.

Teo, H. H., Wei, K. K., \& Benbasat, I. (2003). Predicting intention to adopt interorganizational linkages: an institutional perspective. Management Information Systems Quarterly, 27(1), 19-49. http://dx.doi.org/10.2307/30036518.

Tolbert, T. P. S., \& Zucker, L. G. (1998). The institutionalization of institutional theory. In S. Clegg, C. Hardy, \& W. Nord (Org.), Handbook of organizational studies: analysis models and new issues in organizational studies. São Paulo: Atlas Publishing house.

Yorozu, C. (2017). New institutional entrepreneurship and a celebrity CEO: the role of institutional actors in Japan. Journal of Organisational Transformation \& Social Change, 14(2), 165-185. http://dx.doi.org/10.1080/14779633.2017.1341763. 


\section{Appendix A}

Interview script:

1. Where did the idea of founding a GI come from? How did the registration process take place? (actors, mobilization, strategies, awareness)

2. Was the process linked to the creation of a collective brand?

3. What were the difficulties faced in the process?

- Subcategory Coercive Pressures

- Rules (specific legislation, linked operational procedure, normative instructions, forms)

- Manipulation of sanctions (credit / financial contribution / specific government subsidy)

The authorizations, permissions, delegation, recognition, accreditation are made in what form and for which entities?

4. In light of this, how do you give the structure and arrangement of the producers to request a $\mathrm{Gl}$ ?

5. To whom is it granted, how is the supervision carried out?

- Subcategory Mimetic Pressures

- Model to be followed (reference organization); reference of other Gls to the Cerrado Mineiro Region and to verify if the region itself is a reference for the others in the sector.

- Subcategory Regulatory Press

6. Would it be possible to talk about GI for coffee without professionalization first?

7. Are there charges for training, changing habits, and ways to get the job done?

8. Does the producer have to adhere to them?

9. In what ways can you learn? (self-learning, consulting, technical assistance, hiring specialists, contact with roasters and various buyers)

- Organizational field

10. Which governance structure and structural arrangement is associated with the acquisition of $\mathrm{Gl}$ for coffee in the researched regions?

11. Which organizations have the professionalization of the field? (scientific agriculture, dissemination of best practices, elaboration of POPs / Protocols)

12. Is it necessary to replace the traditional way of doing? (know how to do generational, loss of the domain of the way of doing, or re-signification of know-how) (see procedure for $\mathrm{GI}$ )

13. Does the $\mathrm{Gl}$ of coffee express normative isomorphism (professionalization) different from the wine case? (skills for wine would be more preserved than those employed in coffee?)

14. What new skills are required for coffee production and coffee marketing? (sensorial characteristics, relationship with buyers (roasters, traders, coffee shops ...) acquisition of

- Category Institutional Entrepreneur (focus the role of the State, federal and state sphere)

- Identify organs, government actors that develop entrepreneurial actions;

To verify if these agents are organized, communicate in network, integrated actions.

- Subcategories

- Mobilization of resources

15. How do you see the role of government in this process? (mutual responsiveness?) 
16. Have you received any visits, help, invitations, appeals from government agencies or agents, universities?

17. Have you ever participated in government actions to promote $\mathrm{Gl}$ in other cooperatives, associations, regions?

- Speech

- Formal authority and / or political / social capital (alliance of entrepreneurs with formal / political agents.

- Articulation of alliances / partnerships / agreements

- Discursive strategies (indication and elaboration of problem solving, involvement of others for change)

- Dissemination of meanings (financial gain, acceptance, recognition, belonging, fixation in the property, viable alternative, quality $x$ quantity)

- Propagation of the idea (mobilization initiatives, fairs, trainings and courses, meetings, various facilitators, dissemination to the field, dissemination to external buyers)

- Adequacy of standards (proposed rules $x$ current practices)

18. If so, what are the difficulties of implementing $\mathrm{Gl}$ from the point of view of the standards to be followed?

19. What initiatives and actions have been taken to adapt standards and procedures to producers and vice versa?

20. How do you see the role of government in this process? (mutual responsiveness?)

21. Have you received any visit, help, invitation, recourse by organs or government agents, universities?

- Questionnaire characterization of coffee GI adopters

- Producer profile (large, medium, small)

- Linkage (cooperative, associate, independent)

- Number of producers per region x producers with GI

22. Are there non-registered members?

23. Is there any internal conflict about this?

24. What are the difficulties of introducing new producers? And what initiatives?

25. What percentage of the average premium price paid to the holder with $\mathrm{Gl}$ is always greater?

(are there any data?)

26. Is the coffee notified on delivery to the cooperative and from the buyer to the cooperative?

27. Do buyers (roasters, shopkeepers, coffee shop owners) visit the property or the cooperative? Is information exchange happening, too?

28. Why did you join the GI registry? 